\title{
Microstructure and mechanical properties of TOP-TIG-wire and arc additive manufactured super duplex stainless steel (ER2594)
}

\author{
Xiaoyong Zhang ${ }^{\text {a,b,c }}$, Kehong Wang a,b, ${ }^{\text {, }}$,i Zhou ${ }^{\text {a,b }}$, Jialuo Ding ${ }^{c},{ }^{*}$, Supriyo Ganguly ${ }^{\mathrm{c}}$, Grasso \\ Marzio $^{\mathrm{d}}$, Dongqing Yang ${ }^{\mathrm{a}, \mathrm{b}}$, Xiangfang $\mathrm{Xu}^{\mathrm{c}}$, Philip Dirisu ${ }^{\mathrm{c}}$, Stewart. Williams ${ }^{\mathrm{c}}$
}

\footnotetext{
a School of Materials Science and Engineering, Nanjing University of Science and Technology, Nanjing, 210094, China

${ }^{\mathrm{b}}$ Key Laboratory of Controlled Arc Intelligent Additive Manufacturing Technology, Ministry of Industry and Information Technology, Nanjing University of Science and Technology, Nanjing, 210094, China

${ }^{c}$ Welding Engineering and Laser Processing Center, Cranfield University, Cranfield, MK43 0AL, UK

d University of Hertfordshire, College Lane, Hatfield Herts, AL10 9AB, UK

$*_{1}$ Corresponding author, e-mail : khWang1602@126.com, Tel: +86 025-84315776

*2 Corresponding author, e-mail : jialuo.ding@ cranfield.ac.uk, Tel: 0044750111-5052
}

\begin{abstract}
As the excellent combination of mechanical properties and corrosion resistance for super duplex stainless steel, a prospective method - Wire and Arc Additive Manufacturing - for fabricating this material was proposed, and a wall component was deposited in this study. The microstructure of the as-deposited wall was carefully analyzed along with the variation of mechanical properties. The results revealed that, in the wall-body, the austenite/ferrite phase balance was broken by the overgrowing the austenite phase. During this process, the intergranular secondary austenite leading the increase of austenite phase together with some contributions made by the precipitation of intragranular secondary austenite. Propagation of the intermetallic phases, chi and sigma phase, was not the major reason for the low impact toughness in the last layer area and the root region. Instead, the presence of $\mathrm{CrN}$ and "inclusions" ( $\mathrm{Cr} 2 \mathrm{~N}$ and impurities) took the main responsibility not only in the impact toughness but also the ductility. The anisotropic analysis revealed that the UTS and elongation appeared distinct difference in vertical and horizontal direction samples. The varieties in YS were eliminated by the nitrogen work hardening effect to a large extent.
\end{abstract}

Key words: Wire and Arc Additive Manufacturing; Super duplex stainless steels; $\mathrm{CrN}$; Cr2N; Anistropy; Nitrogen work hardening

\section{Introduction}

Super duplex stainless steels (SDSSs) are widely used in the marine, petrochemical, oil and gas industries owing to their excellent properties in strength and corrosion resistance [1]. The proper balance ratio of austenite to ferrite phase (50/50) is the guarantee of these remarkable properties. However, the higher alloy content and accurate thermomechanical processing of SDSS-wrought products have led to higher costs than normal austenitic stainless steels. Thus, 
it is essential to explore proper manufacturing processes for fabrication of SDSS structural parts.

The wire + arc additive manufacturing (WAAM) technology, a rapid fabrication technology based on layer-by-layer construction [2], is outstanding with high printing efficiency, full density, premium mechanical properties, low cost and relatively high productivity[3]. So far, the WAAM processes predominantly use gas metal arc welding (GMAW), tungsten inner gas welding (TIG/GTAW), cold metal transfer welding (CMT) and plasma arc welding (PAW) for melting the feeding material[4]. Among these, TIG-WAAM provides high-level process control and supplies very clean deposition[5]. A certain amount of high-quality metal components with different materials were produced[6-9]. This promising method reveals high expectations in the area of manufacturing super duplex stainless steel components. Nevertheless, there are few pieces of literature focusing on the integration of such alloy and process. Hence, in this study, some fundamental concerns were carried out.

There are two types of the additive manufacturing method for DSS in recent years, including selective laser melting (SLM) [10-12] and CMT-WAAM [13,14]. The microstructure built by SLM contained nearly $100 \%$ of the ferrite phase. However, $30 \%$ of ferrite phase was found by Posch[13], and between 15 and 27\% was reported by Eriksson[14] with the heat input ranging from 0.4 to $0.87 \mathrm{kj} / \mathrm{mm}$ after using the CMT-WAAM process. This remarkable diversity was mainly due to the higher cooling rate during the SLM manufacturing process. There was not enough time for the transformation of the austenite phase which was happened in the CMTWAAM process. Similar results also found in the microstructure of the laser weld bead of DSS 2205 which presented more than $90 \%$ of ferrite phase owing to the high cooling rate[15]. Differences in the ferrite phase content caused the deviation in micro-hardness and tensile properties. As reported, the micro-hardness maximized to $447.8 \mathrm{HV} \mathrm{[10]} \mathrm{and} \mathrm{450HV} \mathrm{[11]} \mathrm{was}$ mainly due to the increased ferrite content in the microstructure. Exceptional tensile strength around $1321 \mathrm{MPa}$ was achieved mainly due to the random distribution of the crystallographic orientations, high intensity of the dislocations inside the material and the formation of nanosized oxide inclusions and chromium nitride precipitations[11]. These features can be reached in the SLM process as the relatively tiny melt pool size which will be much larger in the WAAM process under the welding power source. Instead, coarsening grains, strong texture and precipitation of deleterious phases can be hardly avoided. That's the reason why much lower tensile strength of the CMT-WAAM made parts were found[13,14]. According to Eriksson[14], lower heat input would cause higher tension strength owing to the more rational austenite/ferrite ratio. Besides, lower impact toughness was also revealed in the high austenite content parts. Which means, except the uneven distribution of ferrite and austenite phases, some other reasons also played an essential role in the fracture of this kind of material. However, the understandings in this area and microstructure characterizations under the as-deposited condition were not fully revealed.

When using TIG-WAAM, the restricted wire feeding angle (intersection angle between wire and depositing plane) restrained the torch flexibility and space accessibility. A mathematical model and confirming experiments showed the optimal angle of $10^{\circ}$ with the wire feed position $5 \mathrm{~mm}$ away from the melting wire tip to the tungsten electrode could ensure the formation of smooth layers[16]. However, this narrow window limited the applications of TIG-WAAM into manufacturing WAAM-based parts for this alloy. TOPTIG[17], owing to the integrated wire feeder of the wire melting process, is more stable than conventional TIG welding with the optimal parameters. The integrated design of wire and torch ensures the liberation of most 
welding postures and makes it more flexible during the deposition. Moreover, the continuous liquid transfer mode is more advantageous than the droplet transfer mode due to the avoidance of spatter generation during deposition. The schematic drawing of these two methods shows the TOPTIG power source is more flexible than traditional GTAW torches (Fig.1) especially in the area of the WAAM process.

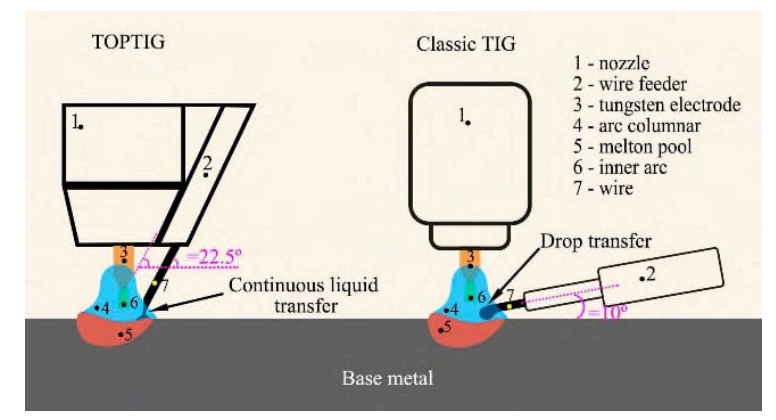

Fig.1 Schematic representation of TOPTIG and classic TIG welding methods. Angle $=22.5^{\circ}$ was used in this study, angle $=10^{\circ}$ was reported by [16].

This work focused on the microstructural and mechanical characterizations of the as-built wall component fabricated by the TOPTIG-WAAM process. The additive microstructure was investigated from the equilibrium phase diagram by using the FactSage software. EBSD tests were carried out to reveal some possible secondary and intermetallic phases mostly found in the weld metal. The relationship between these detrimental phases and the impact or tension properties was ascertained. The further understanding of the tension performance along with the anisotropy was explored and explained via TEM studies.

\section{Material and methods}

The WAAM system used for this study consists of a six-axis FANUC robot, a TOP-TIG power source, a TOP-TIG torch with a push-pull system and a working platform. The shielding gas for WAAM was pure argon (99.9\%). Commercial welding wire with $1.2 \mathrm{~mm}$ in diameter was used, and its chemical composition was listed in Table 1. The deposition parameters were listed in Table 2.

Table 1.

Chemical composition of ER2594 wire (wt.\%).

\begin{tabular}{cccccccccc}
\hline $\mathrm{C}$ & $\mathrm{Mn}$ & $\mathrm{W}$ & $\mathrm{Si}$ & $\mathrm{Cr}$ & $\mathrm{Ni}$ & $\mathrm{Mo}$ & $\mathrm{N}$ & $\mathrm{Cu}$ & $\mathrm{Fe}$ \\
\hline 0.02 & 1.08 & 0.60 & 0.39 & 25.98 & 10.09 & 3.09 & 0.22 & 0.80 & Balance \\
\hline
\end{tabular}

Table 2 .

Process parameters and efficiency of TIG welding [18].

\begin{tabular}{cc}
\hline Electrode-to-workpiece distance & $3.5 \mathrm{~mm}$ \\
\hline Tungsten electrode tip angle & $22.5^{\circ}$ \\
\hline
\end{tabular}




\begin{tabular}{cc}
\hline Deposition Current (I) & $185 \mathrm{~A}$ \\
\hline Deposition Volt (U) & $13 \mathrm{~V}$ \\
\hline Torch Running Speed $(\boldsymbol{v})$ & $3 \mathrm{~mm} / \mathrm{s}$ \\
\hline Heat input $\left(=\mathbf{0 . 6 5} \frac{\boldsymbol{U I}}{\boldsymbol{v}}\right)$ & $0.521 \mathrm{~kJ} / \mathrm{mm}$ \\
\hline Shielding gas and flow rate & Pure Ar $; 15 \mathrm{~L} / \mathrm{min}$ \\
\hline Layer height & $0.8 \mathrm{~mm}$ \\
\hline Interpass temperature & $<100^{\circ} \mathrm{C}$ \\
\hline
\end{tabular}

A single-pass multilayer wall (dimension: $180 \times 125 \times 10 \mathrm{~mm}$ ) under air cooling condition was deposited. The interpass temperature was measured by a handled digital thermometer with the measuring range of $0-200^{\circ} \mathrm{C}$. After deposition, samples were transversely cross-sectioned from the as-built wall for metallographic analysis, tensile and impact tests. The extracting position and dimension of the samples are shown in Fig.2. Metallographic samples were ground, polished for 5-8mins and electrically etched. The electrolyte was a 40wt.\% $\mathrm{NaOH}$ solution. Each sample was etched with 3 volts DC for 8-10 s until the sample surface became straw yellow. The samples were observed by optical microscope (OM, Optiphot Nikon) to get the microstructure photos, then, further detection was conducted by Scanning Electron Microscope (SEM, FEI XL30-SFEG). The EBSD samples were gradually ground, polished for $40 \mathrm{~min}$ and then quantitatively analyzed. The TEM samples were taken through TESCAN Lyra3 dual beam FIB/SEM system and the images were proceeded from the Philips CM10 system. Tensile samples were prepared according to BS EN ISO 6892-1:2009 standard in a rational design to assess the mechanical properties with an Instron 5500R electromechanical testing machine (load cell:50 kN, crosshead speed: $1 \mathrm{~mm} / \mathrm{min})$ at room temperature $\left(20^{\circ} \mathrm{C}\right)$. During the tensile test, the samples were equipped with reflective tape to measure the elongation (parallel length $=32 \mathrm{~mm}$ ) using a laser extensometer. Because of the limited thickness of the as-built wall, the dimensions of Charpy test samples were adjusted to $55 \times 10 \times 2.5 \mathrm{~mm}$ with a $2 \mathrm{~mm} \mathrm{~V}$ notched at the center. The notch tip was pointed to the deposition direction. The impact sample containing the last layer was carefully taken to keep as much as the last layer in it. The tests were carried out at room temperature $\left(20^{\circ} \mathrm{C}\right)$ using a Charpy Leeds Ls102DE impacter.

a

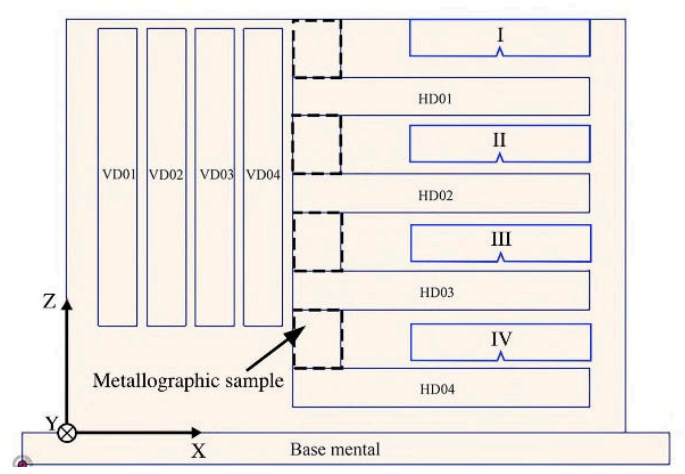

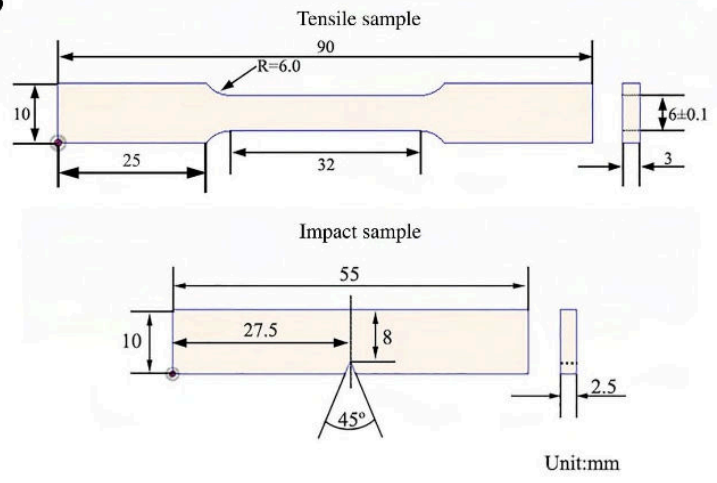

Fig.2 (a) The as-deposited wall along with the positions of the test samples and the coordinate system (b) dimensions of tensile and charpy test samples. 


\section{Results}

\subsection{Thermodynamic calculation}

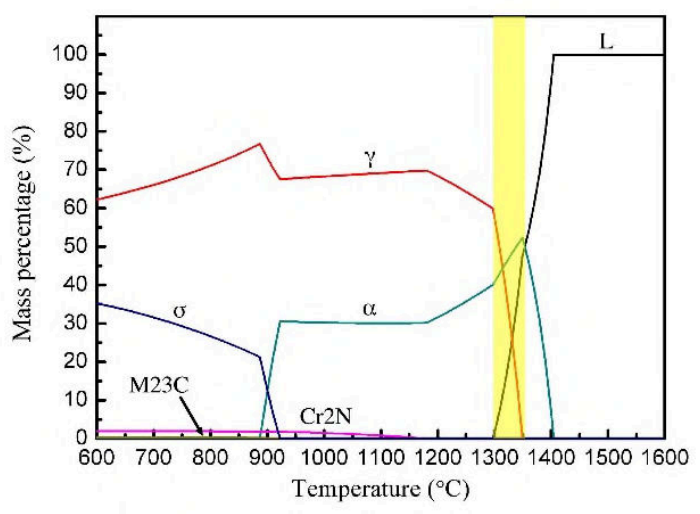

Fig. 3 The equilibrium phase transformation process for ER2594

To the better understanding of the metallurgical behavior of ER2594, the equilibrium phase transformation process was calculated by using the FactSage software with the database FSstel, as shown in Fig. 3. Six kinds of stable phases are confirmed as liquid, ferrite $(\alpha)$, austenite $(\gamma)$, chromium nitride $(\mathrm{Cr} 2 \mathrm{~N})$, sigma $(\sigma)$ and carbide (M23C). Clearly, due to the extensive contents of nickel (10.09 wt.\%) and nitrogen $(0.22 \mathrm{wt} . \%)$ for the design of traditional welding process, the austenite transformation temperature was pushed into the liquid phase region. As a result, a triphase coexistence area appeared as liquid $+\alpha+\gamma$; therefore, it is not possible to form a microstructure with full ferrite. It is worth noting that, although the nickel content is as high as 10.09 wt.\%, the precipitation of $\mathrm{Cr} 2 \mathrm{~N}$ still exists. This phenomenon was not as reported by Zhang[19] that the $\mathrm{Cr} 2 \mathrm{~N}$ would completely disappeare when the Ni content was increased to $7.3 \mathrm{wt} . \%$ in the 2209 duplex stainless steel, which indicates that it is the contents of chromium and nitrogen that makes a significant influence on the driving force of $\mathrm{Cr} 2 \mathrm{~N}$. Besides, the Chi phase disappears in this alloy system as the high nickel content which corresponds to the report of [19]. Moreover, a highly sensitive region to the formation of the $\sigma$ phase was observed from $890-920^{\circ} \mathrm{C}$. For this reason, to get a proper phase balance, the cooling rate in this region should be as quick as possible to minimize the transformation in this area. During the WAAM process, the as-deposited microstructure cannot achieve equilibrium due to rapid cooling in air. Inevitably, the full temperature-field will go through the as-deposited wall; as a result, more ferrite will transfer to austenite at a wide temperature range, sometimes, may attach to the $\sigma$ phase-sensitive region. Overall, an intricate phase transformation can be expected in the asdeposited microstructure.

\subsection{Microstructure evolution}

After carefully checking the whole as-deposited wall, there were three kinds of typical microstructure. They were distributed at the last layer, body and root regions of the wall. Fig. 4 illustrates the head region of the as-deposited wall (a), the details of the last layer (picked by the red dot frame in (a)) (b), and the transition area between the last layer and the wall-body (d). The magnification of the blue rectangular frames in (b) and (d) were shown in (c) and (e), respectively. No pores or macro impurities existed in the wall, and columnar grains grew 
continuously along the deposition direction ( $\mathrm{Z}$ direction) with the ignorance of the layer bands (pointed out by the white arrow in Fig. 4(a)) which were typical characteristics during WAAM with steels[20,21]. In the last layer, the primary austenite took the advantage over the ferrite matrix with the main form of Widmanstätten austenite (WA), a certain amount of grain boundary austenite (GBA) and little intragranular austenite (IGA). The morphology of WA presents side-plate texture and grows from one side of the allotriomorphic GBA. Small acicular IGA propagates in the interior of the ferrite grains. At the transition area, the layer band was illustrated by two sets of red arrows in Fig. 4(d) with the width from $172.2 \mu \mathrm{m}$ to $452.8 \mu \mathrm{m}$. It is clear that higher ferrite matrix content exists in the last layer than in the wall-body. There is a significant growth of austenite under the layer band. More WA and IGA was found in the wall-body than the last layer, as shown in Fig. 4(e). A large amount of WA was cross-sectioned during the sample preparation. Besides, intragranular secondary-austenite precipitation (intragranular $\gamma_{2}$ ) was found just under the layer band, as shown in the white ellipse frame in Fig. 4(e), and the maximum distance between intragranular $\gamma_{2}$ and the layer band was approximately $493.8 \mu \mathrm{m}$.
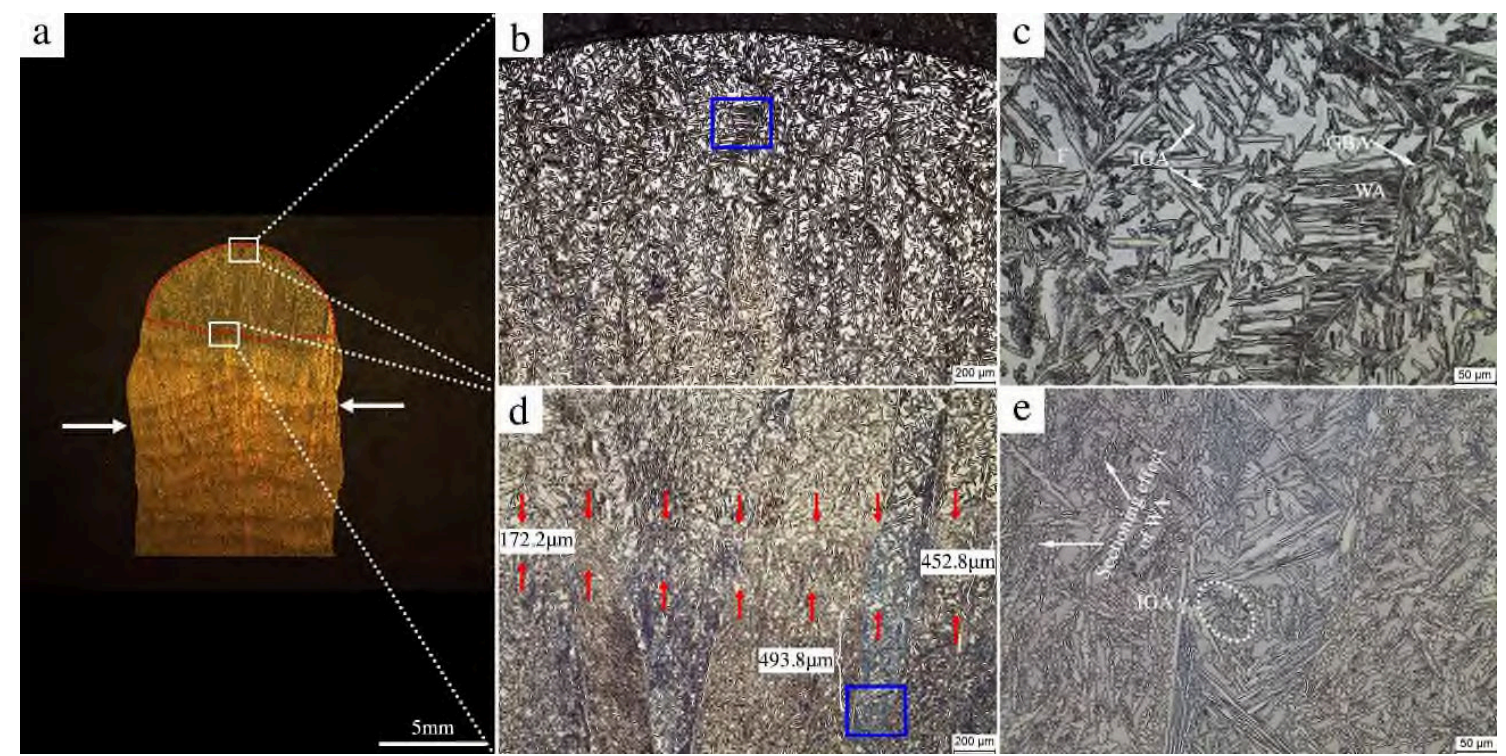

Fig.4 (a) Macro morphology of the head of the as-deposited wall, (b) Microstructure of the last layer and (d) the transition area between the last layer and the wall-body, details in the blue rectangular frames in (b) and (d) were shown in (c) and (e), respectively. Layer band was pointed by two sets of red arrows in (d).

Fig. 5 shows the 3D microstructure of the wall-body (a) and the typical morphologies - the blue rectangular frames - in different facets XY (b), XZ (c) and YZ (d). In the wall-body, the austenite phase almost full fills the ferrite columnar grains in the scope. From the cross-section of a single columnar in XY facet, parallel side-plate WA occupies the majority space in the ferrite columnar, and some IGA scattered in the extra room. The textures in the $\mathrm{XZ}$ and $\mathrm{YZ}$ facets reveal similar features. Both of them consist of longitudinal sections of ferrite columnar grains which are inundated with austenite phase and layer bands, as shown in Fig. 4(a). Similar to the transition area in Fig. 4(d), a certain amount of intragranular $\gamma_{2}$ was also found under the layer bands both in XZ and YZ facet, as shown in the white ellipses in Fig. 5(c,d), and the maximum distance from the layer band is around $316.0 \mu \mathrm{m}$. Upon the intragranular $\gamma_{2}$ forming area, a certain amount of partially transformed austenite (PTA) appeared in the layer band in the form of the plateau. Which means the peak temperature in the layer band reached the 
melting point. However, due to a certain amount of austenite and a restrained transformation of ferrite in this region, it can be hypothesized that the layer band entered a triphase coexistence region - partially melting area (PMA) - with the temperature just above $1300^{\circ} \mathrm{C}$ according to the equilibrium calculation. The width of the layer band differs from 174.0 to $222.2 \mu \mathrm{m}$.

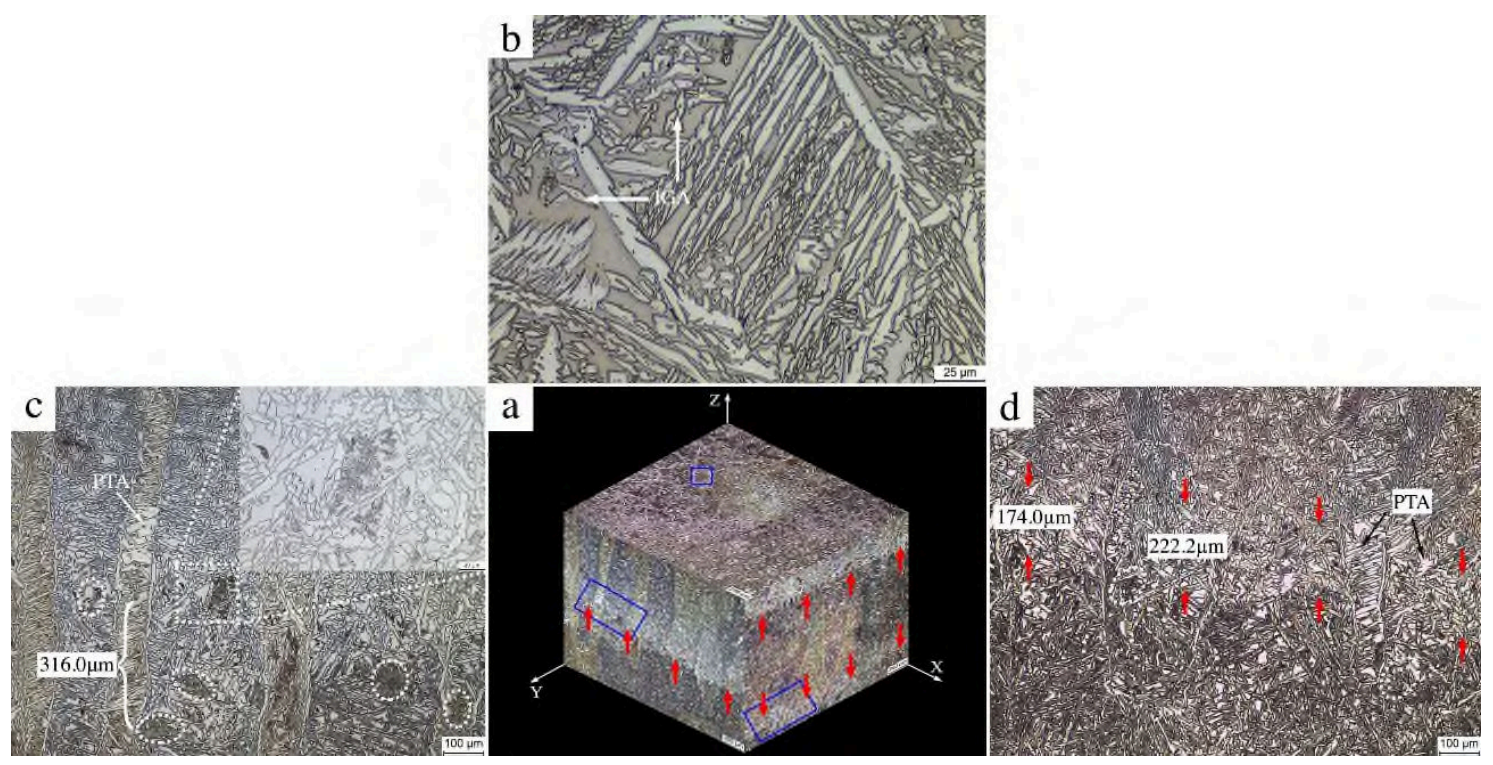

Fig. 5 (a) 3D microstructure of the wall-body (taken from the centre of the wall), details in the blue rectangular frames in XY, XZ and YZ faces were shown separately in (b), (c) and (d). Layer bands were shown by sets of red arrows.

Fig. 6 illustrates the root region microstructure of the as-deposited wall (a) and its detail information in the selected blue rectangular frame (b) with different etching strategy. In this case, the austenite phase can also be well separated from the ferrite matrix, and the intragranular $\gamma_{2}$ generation area was more distinct than the previous method. However, it is hard to differentiate the ferrite columnar grain boundaries as pointed by white arrows in Fig. 6(a) and the layer band as shown by two sets of red arrows in Fig. 6(b). The width of the layer band ranges from 187.7 to $250.3 \mu \mathrm{m}$. In the root region, the austenite phase also predominates the microstructure, and the ferrite matrix reveals a small amount. However, the content of the ferrite phase in the root region is more than that in the wall-body area. In the layer band, PTA was also observed as plateau morphology, and intragranular $\gamma_{2}$ still existed under the layer band, as shown in Fig. 6(b). The maximum distance from the intragranular $\gamma_{2}$ to the layer band is around $351.1 \mu \mathrm{m}$.

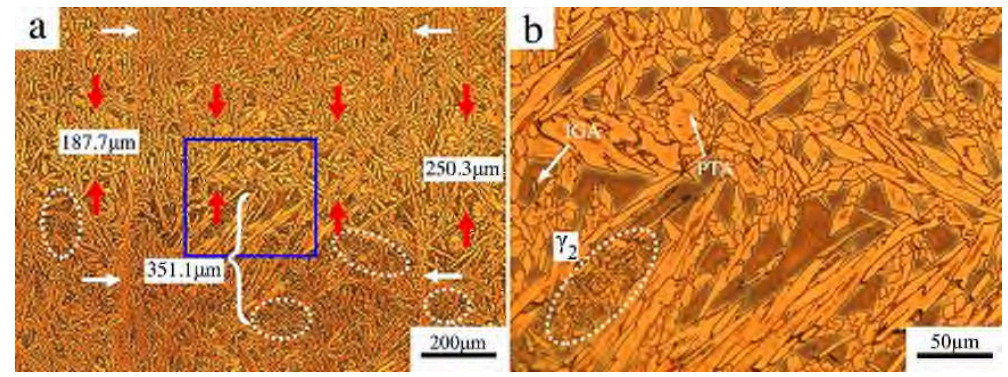

Fig. 6 (a) Microstructure of the root region of the as-deposited wall, local information in the blue rectangular frame was shown in (b). The layer band was picked by two groups of the red arrows. Electronic etch corrosive was changed from $10 \%$ oxalic acid to $40 \%$ sodium hydroxide alcoholic solution. 


\subsection{Microhardness and impact toughness distributions}

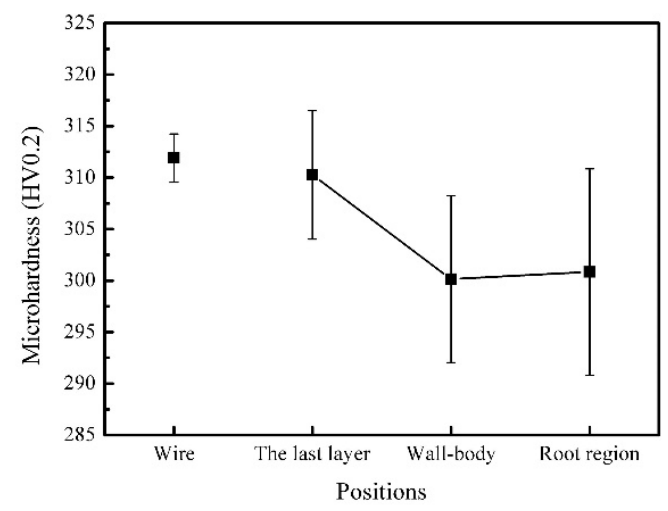

Fig. 7 Microhardness distribution trends from the last layer to the root region, as a contrast, wire microhardness was draw separately. (Processing interval $0.1 \mathrm{~mm}$ )

Fig. 7 depicts the microhardness trends of the as-deposited wall from the last layer to the root region as well as the wire with error bars calculated by STDEV function in excel. The processing interval is $0.1 \mathrm{~mm}$, and at least 20 points were collected in each position. The average microhardness in the ER2596 wire was the highest when compared with that in different locations in the as-deposited wall. A considerable decrease of the microhardness from the last layer to the wall-body was found, and, in the root region, there was a slight rise of the microhardness. This change is strongly linked to the ferrite and austenite balance in different positions. Form the error bars, the fluctuation in the as-deposited wall is much higher than that in the wire due to the uneven distribution of austenite and ferrite phases, or some possible intermetallic phases (sigma phase) and precipitations (chromium nitrides) which are likely to generate under the complicated thermal situation during deposition, as pointed out by the equilibrium calculation Fig. 3. Recalling Fig. 5, it is noted that the microhardness trends are accompanied by the decrease of ferrite phase and increase of austenite phase in the as-deposited wall. Only the microhardness in the last layer closes to that of the wire which means a similar phase balance between these two positions can be expected.

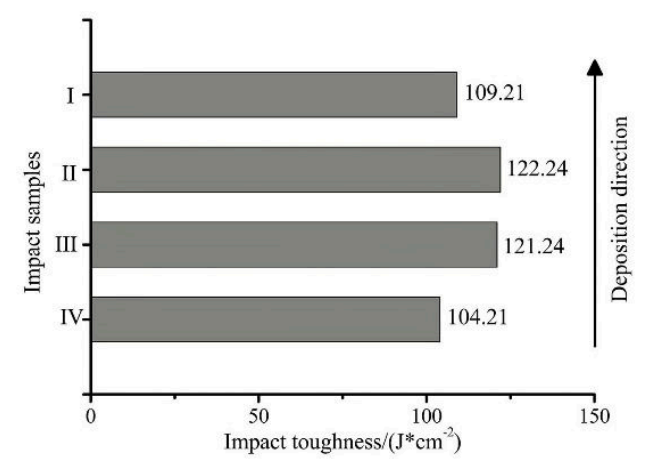

Fig. 8 Impact toughness changes in the deposition direction

As can be seen from Fig. 8, the highest impact toughness was observed in the wall-body area with the values around $121.74 \mathrm{~J} / \mathrm{cm}^{-2}$, similar values are found in the head $\left(109.21 \mathrm{~J} / \mathrm{cm}^{-2}\right)$ and $\operatorname{root}\left(104.21 \mathrm{~J} / \mathrm{cm}^{-2}\right)$ regions. Meanwhile, the lowest microhardness appeared in the wall-body 
area where the austenite phase occupied most of the microstructure. It can be predicted that, with the increase of the austenite phase content, the decrease of microhardness and improvement of ductility can be foreseeable. This phenomenon is acceptable due to the FCC lattice has a higher deformation ability than the BCC crystal structure[22]. The lower toughness in the root region (Fig.6) also gives a transparent verification to this speculation as a little higher ferrite was found than that in the wall-body (Fig. 5). However, the impact toughness value in the head region is lower than that in the wall-body but slightly higher to the performance in the root region. According to[1,22,23], phase balance, intermetallic phases and chromium nitrides prominently affect the impact toughness for DSSs. Considering the height of the last bead (-4mm from the center line), which means, apart from the last bead, the support layers adjacent to the last bead also played an un-neglectable adverse impact on the toughness. However, based on the microstructure analysis in the head region (Fig. 3), there are no apparent differences between these support layers and the wall body. A proper speculate is that some detrimental phases may be formed during the running of the last bead in these layers due to complex thermal field[20]. As a result, the lower ductility was caused.

\subsection{Tensile properties in vertical and horizontal directions}

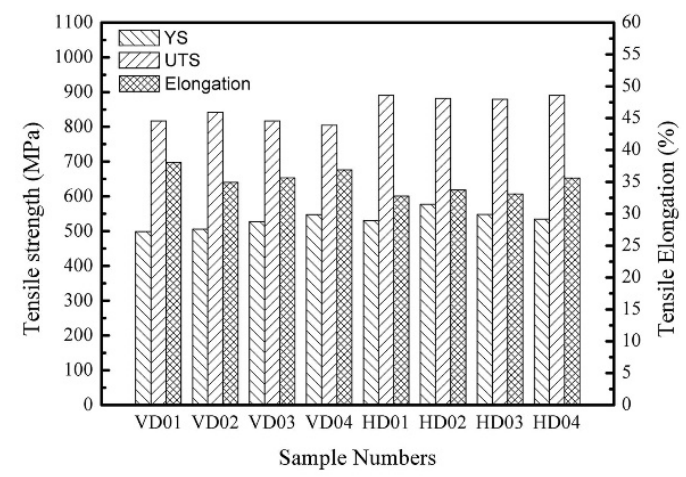

Fig. 9 Yield strength (YS), ultimate strength (UTS) and elongation performance in vertical direction (VD) and horizontal direction (HD) samples.

Fig.9 shows the tensile properties and elongation of the samples in the vertical direction (VD) and horizontal direction (HD). The anisotropy was observed in the ultimate strength (UTS) and elongation performance in these two orientations, with the varieties of $38-86 \mathrm{MPa}$ in UTS and $0-5.3 \%$ in elongation. Nevertheless, the yield strength (YS) in these two directions are near equals which indicates similar deformation mechanism taking place regardless of different tropism. This phenomenon was also observed when using CMT-WAAM method to fabricate high nitrogen stainless steel parts in our previous work[21]. The similarities and disparities will be discussed later.

From the cross-section of the VD and HD samples, as shown in Fig. 10 (a) and (b), a distinct feature can be drawn that more austenite phase participates during the breaking-down process in the VD sample, and dramatic deformation happened in the austenite phase especially the side-plate WA, as shown in Fig. 10 (a). For more details, in Fig. 10(c), it can be seen that the ferrite phase was extruded backwards, and the participant austenite breaking-down along with the formation of dimples. A previous report from Zhang[24] noted that the precipitation of intragranular $\gamma_{2}$ was beneficial to the tension properties by forming dense, fine dimples; 
however, the reasons were not given. In this study, one possible cause can be seen that the movement of deformed WA was impeded by the intragranular $\gamma_{2}$ which can be seen both in the VD (Fig. 10(a)) and HD (Fig. 10(b)) samples. The highly deformed WA was not found in the HD sample, and the fracture positions revealed none preferred sites in austenite or ferrite (in Fig. 10(d)). As a result, voids can be easily discovered with sharp edges (Fig. 10(d)). The quite different performance of WA in VD and HD samples during the tension process will be studied in our future research.
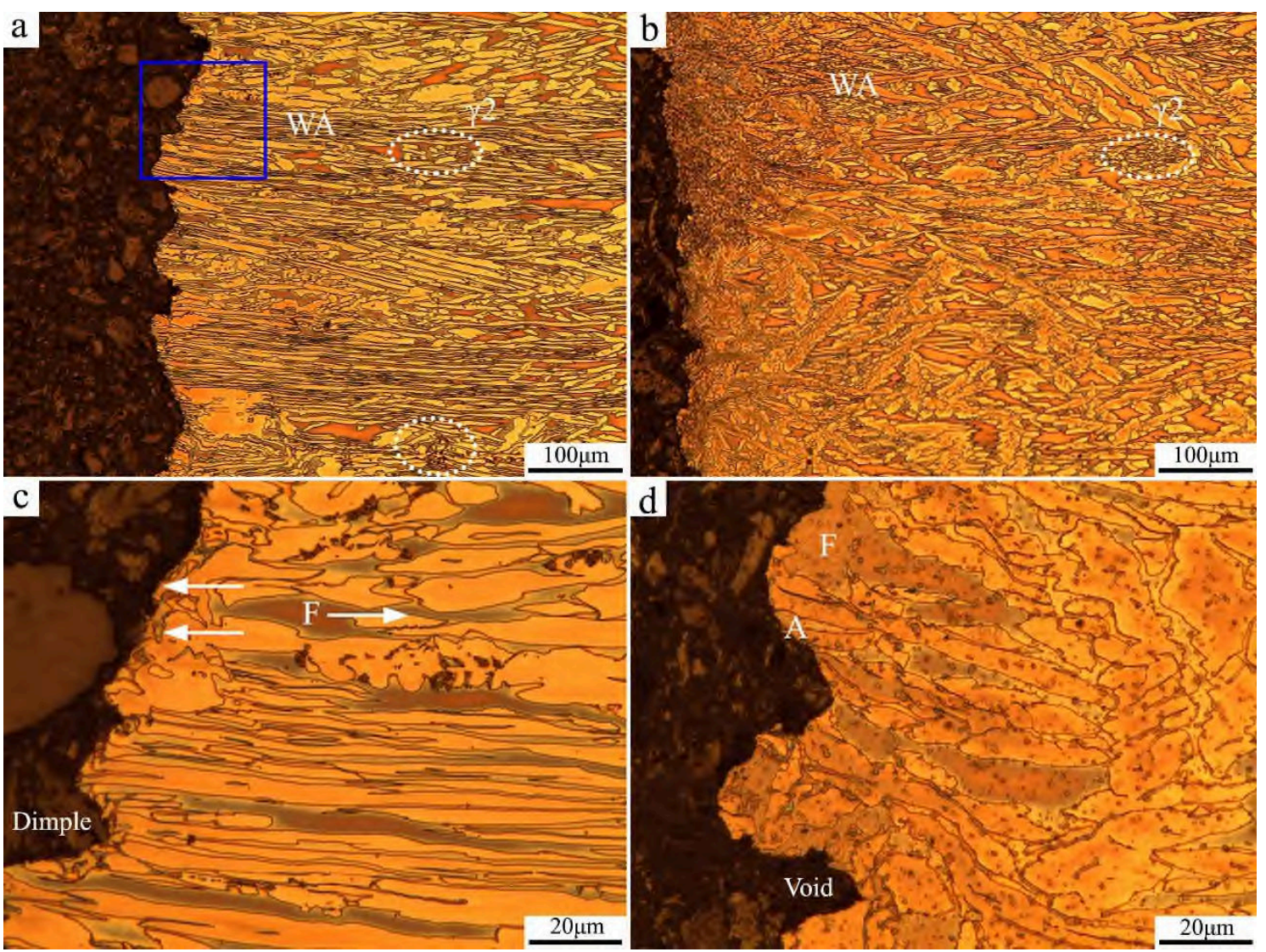

Fig.10 The etched cross-sections of (a) the VD and (b) HD samples. The details in the blue rectangular frame in (a) was shown in (c), and a selected zone which was not shown in (b) from the HD sample was shown in (d). The white arrows in (c) represent the extrude directions of austenite and ferrite during the breaking-down process.

\section{Discussion}

\subsection{Secondary austenite transformation}

A certain amount of work, in the field of welding duplex stainless steels, has devoted constructive research in the microstructure evolution after reheating the fusion region[25-27] and the heat affect zone (HAZ) [19,28,29]. It was found that secondary austenite generated both in the reheating fusion region and the reheating HAZ in the form of intragranular $\gamma_{2}$ and intergranular $\gamma_{2}$. Commonly, the intragranular $\gamma_{2}$ presents delicate particle clusters in the interior of ferrite grains, as observed in Chapter 3.2, also as shown in Fig. 11(a). In this study, these clusters located $0-493.8 \mu \mathrm{m}$ from the layer bands. Differently, the intergranular $\gamma_{2}$ shows the texture of thin films on the periphery of primary austenite $\left(\gamma_{1}\right)$, as demonstrated by 
magnification in Fig. 11 (b). The common idea comes from Ramirez[26] and Atamert[28] that the amount of secondary austenite depends mainly on cooling rate, inclusion content and grain size for a given alloy component. Smaller ferrite grain size could promote the transformation of austenite pointed by[29,30]. As the columnar ferrite grains in this work, the effect of grain size on the secondary growth of austenite can be neglected. Involuntarily, cooling rate and the inclusion content provided the main driving force for the intense propagation of the secondary austenite. Considering the short distance from the intragranular $\gamma_{2}$ to the layer band (that is PMA), it can be speculated that the peak temperature in this area is high enough to provide suitable time to form intragranular $\gamma_{2}$ as well as intergranular $\gamma_{2}$. That's why these two kinds of $\gamma_{2}$ were observed simultaneously in Fig. 11 (a) under this alloy system. After comparison the intergranular $\gamma_{2}$ and the $\gamma_{1}$ by imaging from the backscatter electrons, as shown in Fig. 11(b), the brighter area was shown in $\gamma_{1}$, and the darker area was revealed as the intergranular $\gamma_{2}$. As pointed by [26], $\gamma_{2}$ formed at a higher temperature (more than $1100^{\circ} \mathrm{C}$ ) had higher $\mathrm{Cr}$ and $\mathrm{N}$ content in it. According to the results detected by the EDS line scan (the yellow line in Fig. 11(b)), Cr was confirm had higher content in the intergranular $\gamma_{2}$, as figured out by the blue ellipse. Besides, due to $\mathrm{N}$ has lower outer electrons that makes its concentration region falling into the shade. In this case, the intergranular $\gamma_{2}$ was the dark region which means higher nitrogen content can be expected in this area. Ramirez[31] proposed a cooperative precipitation mechanism for intergranular $\gamma_{2}$ growth at the ferrite- $\gamma_{1}$ interface. $\mathrm{Cr}_{2} \mathrm{~N}$ first nucleates at the inter-phase interface which causes a local depletion of ferrite promoting elements $\mathrm{Cr}$ and $\mathrm{Mo}$. The depletion provides suitable nucleation sites for $\gamma_{2}$ and subsequent growth. The original $\mathrm{Cr}_{2} \mathrm{~N}$ precipitations are trapped in the new austenite and dissolved quickly, resulting in higher $\mathrm{Cr}$ and $\mathrm{N}$ contents in the new secondary austenite. As a result, the increase of $\mathrm{Cr}$ accompanied by the raising of $\mathrm{N}$ in this area, causing the darker image in the intergranular $\gamma_{2}$. During this process, austenite promoting element - nickel - will diffuse to the new austenite[32], which was confirmed by EDS liner scan results in the embedding graph in Fig. 11(b). The cooperative precipitation mechanism for intergranular $\gamma_{2}$ was further verified in this study.

Since the high peak temperature existed in this area along with the air-cooling process, there were enough time and diffusion rate for the diffusion-controlled precipitation of intragranular $\gamma_{2}$, let alone the nucleation of this kind of precipitations accelerated by inclusions (Fig. 11(b)). Nevertheless, previous research revealed that intragranular nitride dissolution played an essential role in the intragranular $\gamma_{2}$ precipitation $[33,34]$. For traditional duplex stainless steels, at such a high temperature (more than $1100^{\circ} \mathrm{C}$ ), the intragranular nitride will dissolve rapidly, and can hardly act as an inoculant for intragranular $\gamma_{2}$. In this alloy system, with the assistance of high contents of austenite promoting elements, $\mathrm{Ni}, \mathrm{N}$ and $\mathrm{W}[31]$, the temperature of intragranular $\gamma_{2}$ predominance may be pushed up to $1180^{\circ} \mathrm{C}$ where $\mathrm{Cr} 2 \mathrm{~N}$ is still stable (Fig. 3). In this case, intragranular $\gamma_{2}$ will heterogeneously nucleated at the intragranular nitrides. However, the observation of this nucleation is problematic because of two reasons. The first is the trapped intragranular nitrides inside the austenite will promptly be dissolved. On the other hand, the etching methods can attack the nitrides and remove them, just leaving the small holes behind, as shown in Fig. 12. As a result, the bunches of intragranular $\gamma_{2}$ can be easily found in this area just below the PMA (layer band) area, also observed by Atamert[26] in the reheated HAZ nearby the fusion line. In this study, this area was named as high-temperature melt pool affect zone (HT-MPAZ). In the space below the HT-MPAZ, coarse austenite was also found with the growth of intergranular $\gamma_{2}$ at a lower temperature. Moreover, as there was none unaffect fusion area located in the rest region (Fig. (4-6)), it can be deduced that the remaining 
part was affected by lower temperature and coarsened by the continuous growth of intergranular $\gamma_{2}$. The phase distribution in a typical single layer in one single layer will be discussed next.
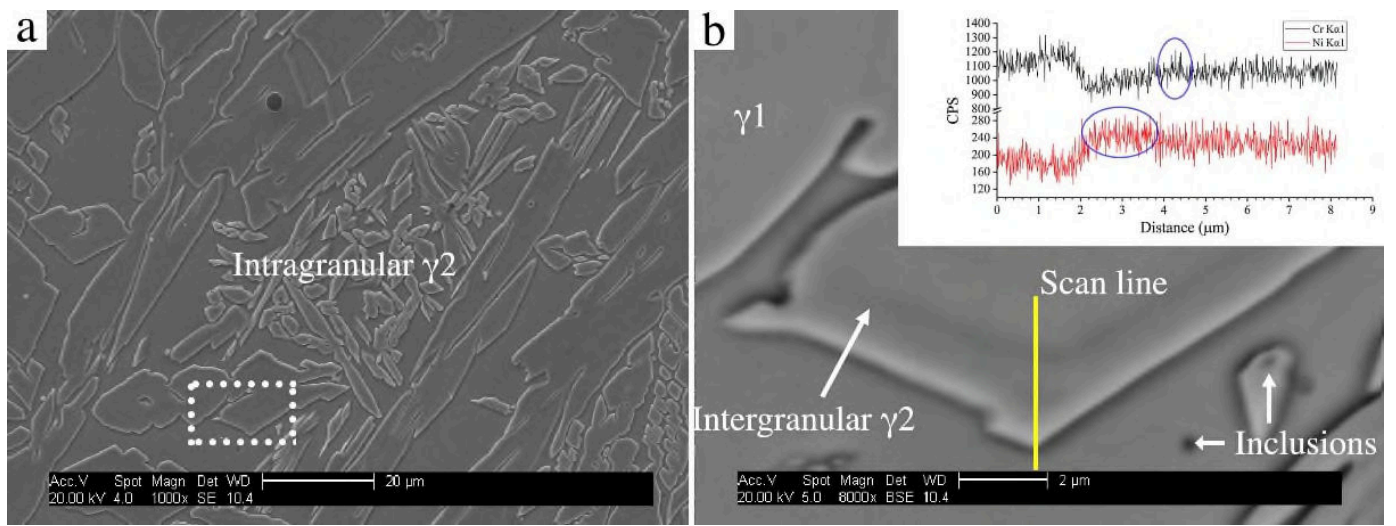

Fig. 11 (a) SEM image of the intragranular $\gamma 2$ precipitation region in the wall-body and (b) the magnification of the intergranular $\gamma 2$ growth from the primary austenite $(\gamma 1)$ in the white rectangular frame. The information of the yellow EDS scan line was shown in the embedding graph in (b).

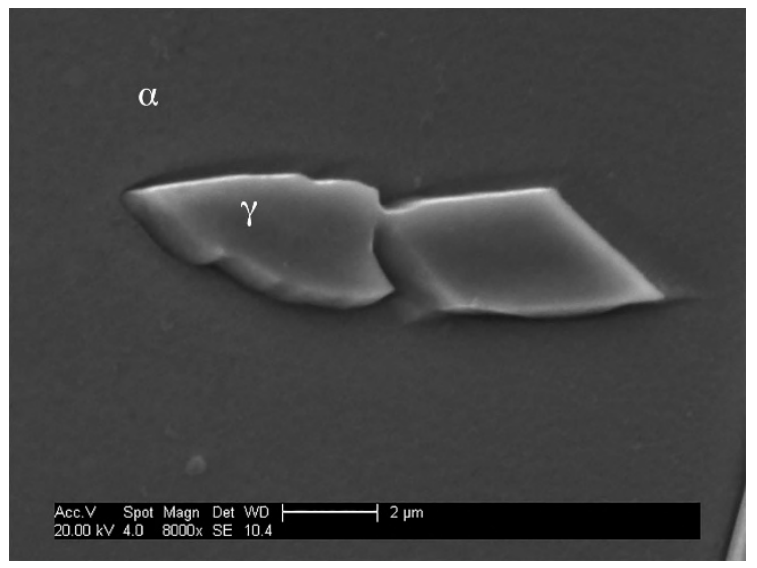

Fig. 12 SEM image of the intragranular austenite particle with internal hole left by particles removed during the etching process.

\subsection{Microstructure distribution in one single layer}

a

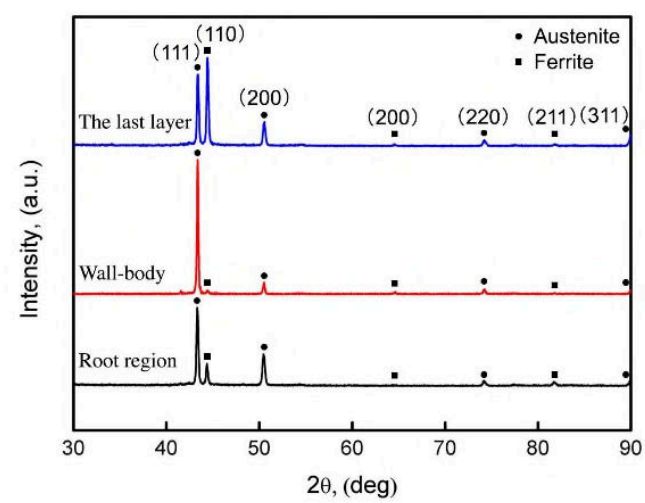

b

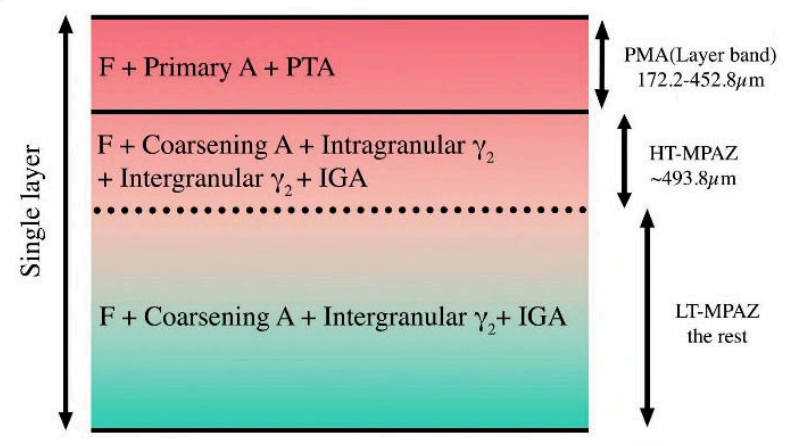

Fig. 13 (a) XRD results in different positions and (b) phases distribution in a single layer in the wall-body area. 
For the phase information, three typical positions, the last layer, wall-body and root region, in the as-deposited wall were prepared for the XRD test, and the patterns were shown in Fig. 13(a). There were mainly two phases (austenite and ferrite) with no more evidence of the intermetallic phases (sigma or chi phases) or precipitations (chromium nitrides or carbides). Their low contents which will be discussed later may claim for the major responsibility. Usually, the lowest surface energy for the growth of the FCC and BCC crystal is propagated along their close-packed planes: (111) $\gamma$ and $(110)_{\alpha}$. This growing principle is obeyed in this work. In general, the higher integrating area or intensity of the main peak of one phase meant more content than the other[19,35]. From the qualitative analysis, almost balanced phase contents can be expected in the last layer. Massive austenite phase can be seen in the wall-body and the root region. However, a little more ferrite phase is shown in the root region than the wall body. This result accorded perfectly with the microstructure observation in Chapter 3.2. Further analysis of the XRD patterns was proceeded for the calculation of the content by using PDF\#52-0513 for FCC and PDF\#06-0696 for BCC. The austenite and ferrite phase contents were achieved regardless of the intermetallic phases and precipitations contents, as shown in Table 3. After reheating by adjacent layers, much more austenite phase was formed. For the visual presentation of the increase of the austenite phase, the distribution of phases in one single layer based on the microstructure features observed from the wall-body was depict in Fig. 13(b). According to the temperature-dependence precipitation mechanism analyzed above, the presence of PTA and intragranular $\gamma_{2}$ sliced one single layer into three parts, namely layer band (PMA), HT-MPAZ, and LT-MPAZ. It can be easily seen that the coarsening austenite, $\gamma_{2}$, and IGA takes the primary responsibility to the dramatic increment of austenite content. Among these, coarsening austenite predominated the contribution both in HT-MPAZ and LT-MPAZ, and the IGA provided minor assistance to the increase of austenite content. The intragranular $\gamma_{2}$ only contributed to the austenite content in the HT-MPAZ.

As discussed in 4.1, the coarsening effect of austenite was led by the growth of intergranular $\gamma_{2}$ in the frontier of the $\gamma_{1}$ in a wide temperature range. PTA always formed in the closed positions to the melt pool; in other words, the fusion line region in the welding process[28,36]. The appearance of PTA indicates the partially melted area (PMA) formed the layer band in this case. Interestingly, the content of the ferrite phase in this area showed no distinct increment which differences from the findings reported by[32,37,38]. The reasons can be marked as, firstly, higher nitrogen content lifts the austenite transformation temperature[39]; secondly, higher nickel content $(10 \mathrm{wt} . \%)$ promotes the ferrite solves temperature by increase the nickel equilibrium value[1]; thirdly, PTA and primary austenite effectively hinders ferrite phase growth and inhibits the partition of $\mathrm{Cr}$ and $\mathrm{Mo}$ [40]. Recalling chapter 4.1, in the hightemperature region, both $\gamma_{2}$ (intergranular/intragranular) were observed. However, when the peak temperature decrease, only the intergranular $\gamma_{2}$ can be expected in the LT-MPAZ with the evidence of massive coarsening austenite. A small amount of IGA was observed scattering in the interior of ferrite grains with inclusions or chromium nitrides acted as nuclei, as shown in Fig. 5(b), Fig. 6(b), Fig. 11(b) and Fig. 12.

Table 3 Austenite and ferrite phase contents in different positions in the as-deposited wall (regardless of intermetallic phases and precipitations contents).

\begin{tabular}{cccc}
\hline & The last layer & Wall-body & Root region \\
\hline Austenite (wt. \%) & 51.78 & 98.45 & 84.77 \\
Ferrite (wt. \%) & 48.22 & 1.55 & 15.23 \\
\hline
\end{tabular}


In general, with the repeating of thermal cycles, the as-deposited microstructure undergoes complex transformations, and almost every kind of austenite phase can be seen in the microstructure. With careful analysis and the help of equilibrium diagram, the microstructure features were classified and revealed in one single layer according to the temperaturedependence transformation mechanism. In the layer band, $\gamma_{1}$ and PTA predominated the austenite phase in the ferrite matrix. The majority of coarsening austenite, some $\gamma_{2}$ (intergranular/intragranular) and minor IGA were revealed in the HT-MPAZ. The microstructure in the LT-MPAZ was almost the same with that in the HT-MPAZ except for the absence of intragranular $\gamma_{2}$.

\subsection{Generation of the intermetallic phases and precipitations}

Table 4 Database with crystallographic geometry parameters for EBSD phase identification.

\begin{tabular}{cccccc}
\hline Phase & Space group & $\mathrm{a}$ & $\mathrm{b}$ & $\mathrm{c}$ & Database code (AMCSD) \\
\hline$\gamma / \gamma 2$ & $\mathrm{Fm} 3 \mathrm{~m}$ & 3.5950 & 3.5950 & 3.5950 & 0019406 \\
$\delta$ & $\mathrm{Im} 3 \mathrm{~m}$ & 2.8660 & 2.8660 & 2.8660 & 0000670 \\
$\operatorname{Sigma}(\sigma)$ & $\mathrm{P} 42 / \mathrm{mnm}$ & 8.8 & 8.8 & 4.544 & 0017754 \\
Chi $(\chi)$ & $\mathrm{I} 43 \mathrm{~m}$ & 8.92 & 8.92 & 8.92 & 0017755 \\
CrN & Fm3m & 4.140 & 4.140 & 4.140 & 0019174 \\
\hline
\end{tabular}

EBSD was introduced to detect the intermetallic phases and precipitations which could not be revealed by the XRD patterns. According to the previous work[21], the chromium nitride generated during deposition was mainly $\mathrm{CrN}$, namely quenched-in nitride[23]. The crystallographic information for EBSD phase identification was shown in Table 4. The scanning step was set between $0.0524-0.3386 \mu \mathrm{m}$ to get elaborate notes of these minor phases. Three positions were selected, the top layer, wall-body and the root region. Table 5 lists the contents of the intermetallic phases $(\sigma / \chi)$ and CrN measured by EBSD. Due to the high magnification of the view location, there may be a slight deviation from the actual value. However, from the aspect of the evolutionary tendency of different phases, it can be used for reference. The amounts of $\sigma$ and $\chi$ are relatively lower than the $\mathrm{CrN}$ content in the as-deposited condition. From the equilibrium phase diagram (Fig. 3), $\chi$ phase is not a stationary phase in this alloy system, and during reheating by the adjacent layers, it will be quickly dissolved, also reported by $[41,42]$. The reason for the formation of $\chi$ phase during deposition may be the high amount of tungsten (W 0.6wt. \%) in the feeding wire that improved the transformation temperature. However, $\sigma$ phase is a thermodynamically stable phase, and it can be formed during ageing between $600-1000^{\circ} \mathrm{C}$ depending on alloy components[43-45]. For duplex stainless steel, the quickest precipitation of sigma phase happens around $900^{\circ} \mathrm{C}$ with the perfect nucleation sites provided by the austenite/ferrite interface[46]. In this study, the $\sigma$ phase can easily exist under $920^{\circ} \mathrm{C}$. With the experience from[42], sigma phase can be avoided during the welding process by reducing the heat input and the interpass temperature. The quite low content of this phase in the as-deposited wall indicated the quick pass of the temperature during the sensitive area $\left(890-920^{\circ} \mathrm{C}\right)$. Besides, with the low heat input $(0.521 \mathrm{~kJ} / \mathrm{mm})$ and proper interpass temperature $\left(<100^{\circ} \mathrm{C}\right)$, the sigma phase content was further controlled. Moreover, $\mathrm{CrN}$ revealed a powerful ability to prevent the precipitation of sigma phase. As reported by $[39,47,48]$, with the addition of nitrogen, the high-temperature diffusion coefficient of $\mathrm{Cr}$ and Mo was retarded, inevitably, the steel is less sensitive to intermetallic phase precipitation. In 
this case, with the combination of proper process parameters and nitrogen alloying, precipitation of $\sigma$ and $\chi$ were restrained to a great extent. However, the side-effect is also evident as a certain amount of $\mathrm{CrN}$ was revealed with the high nitrogen content $(0.22 \%)$ in the wire. Fig. 12 taken from the wall-body area depicts that $\mathrm{CrN}$ favoured two kinds of locations: firstly, distribution in the ferrite phase randomly; secondly, assembling on the austenite and ferrite interface. The former feature was resulted by the relatively low solubility of nitrogen in ferrite than that in austenite. During the cooling process in the deposition, the ferrite phase was saturated with nitrogen which provided a suitable environment to the propagation of chromium nitrides. Pettersson[23] calculated the driving force of chromium nitrides, it was found that the driving force for $\mathrm{CrN}$ formation increased to a close level of that for $\mathrm{Cr} 2 \mathrm{~N}$ when the temperature was below $1000^{\circ} \mathrm{C}$. As a result, the appearance of $\mathrm{CrN}$ was well reasoned considering the very small misfit between the ferrite and $\mathrm{CrN}$ cube planes compared to $\mathrm{Cr} 2 \mathrm{~N}$ when cooling rapidly. Therefore, a certain amount of $\mathrm{CrN}$ was found in the ferrite phase. The accumulation of $\mathrm{CrN}$ in the austenite and ferrite interfaces provided suitable growing sites for the intergranular $\gamma_{2}$ with the mechanism discussed in 4.1. As the growing of intergranular $\gamma_{2}$ is a diffusion-controlled process, either the precipitation of $\mathrm{CrN}$ or $\mathrm{Cr} 2 \mathrm{~N}$ will cause the austenite promoting elements gathering around them. As a result, the growth of the intergranular $\gamma_{2}$ was accelerated. It is worth noting that there is a certain amount of inclusions existed in the deposited structure, as shown in Table 5. After carefully checking the EBSD map, some "inclusions" were found in the interface between the intergranular $\gamma_{2}$ and the ferrite, as shown by the embedding image in Fig. 12 (b). Considering the intergranular $\gamma_{2}$ growth mechanism, these "inclusions" are most likely $\mathrm{Cr} 2 \mathrm{~N}$. In this case, the inclusions detected here were made up of $\mathrm{Cr} 2 \mathrm{~N}$ and impurities.

Table 5 The contents of the intermetallic phases $(\sigma / \chi)$ and CrN revealed by EBSD analysis.

\begin{tabular}{cccc}
\hline & The last layer & Wall-body & Root region \\
\hline$\chi($ wt. ppm) & 569 & 37.1 & 31.8 \\
$\sigma$ (wt. ppm) & 3.39 & 2.4 & 97.1 \\
CrN (wt. \%) & 1.57 & 2.44 & 0.88 \\
Inclusions & 2.93 & 3.21 & 4.12 \\
\hline
\end{tabular}

Generally speaking, the presence of $\sigma, \chi$, chromium nitrides and impurities dramatically deteriorated both impact toughness and tensile properties. In this study, due to the meager contents of $\sigma$ and $\chi$, their side effects to the mechanical properties were not a significant factor. As a result, the low impact toughness in the head and root region was caused mainly by more contents of ferrite phase (Table 3) and the presence of inclusions ( $\mathrm{Cr} 2 \mathrm{~N}$ and impurities). The effect of $\mathrm{CrN}$ on the impact toughness was not assured as more $\mathrm{CrN}$ existed in the wall body where the impact toughness was the highest. From the research of Simmons, $\mathrm{CrN}$ did not reveal a distinct side effect to the impact toughness of the aged high nitrogen stainless steels. It can be speculated that the appearance of $\mathrm{CrN}$ was not the main reason for the low impact toughness. However, the elongation of the HD samples was visibly improved in the low content of $\mathrm{CrN}$ sample (HD04), as shown in Fig. 8. 


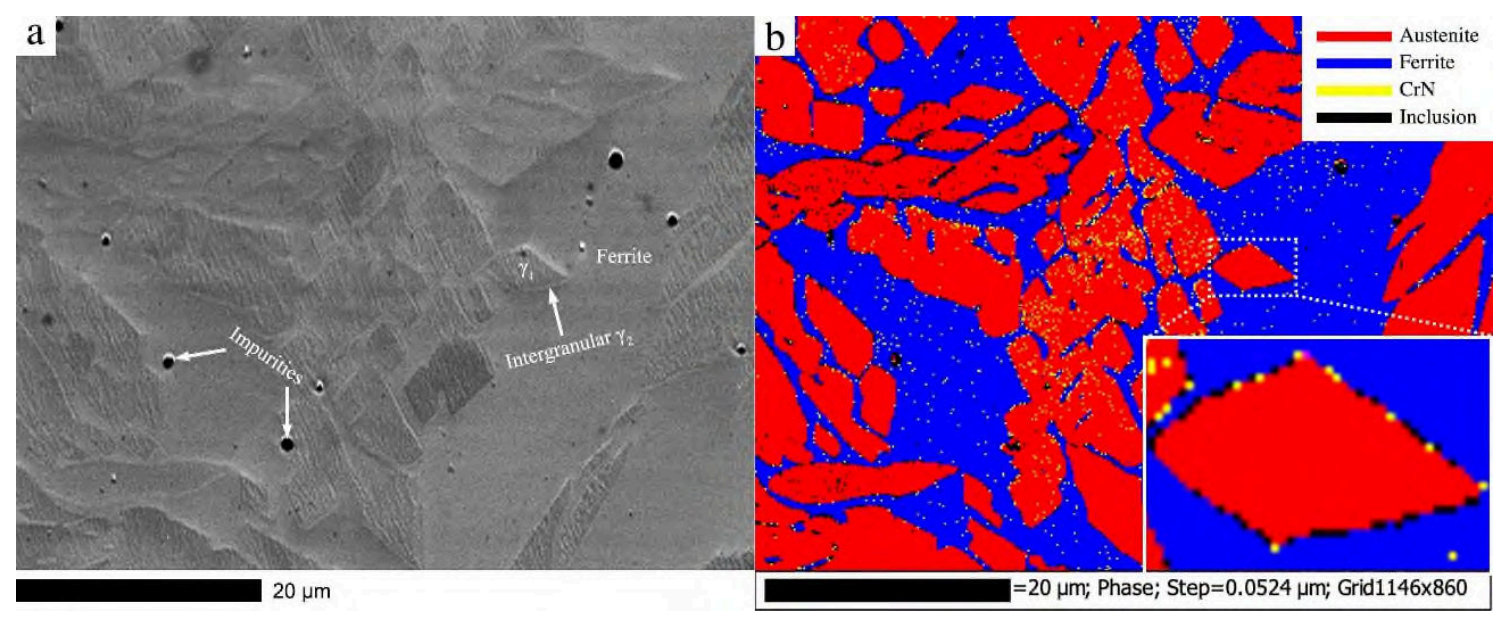

Fig. 12 (a) SEM image of the micro zone taken from the wall-body and (b) the corresponding EBSD phase image in this area.

\subsection{Anisotropic analysis}

From Fig. 9, the tensile properties were different in ultimate strength (UTS) and elongation in VD and HD samples. The anisotropy was distinct from the difference of 38-86 MPa in UTS and $0-5.3 \%$ in elongation. Some main reasons were summarized, 1): Directional ferrite columnar propagated along the as-built direction which provided a natural property of anisotropy; 2): More slip systems of the FCC structure in the VD samples were brought into operation which can be seen from the extrude effect of ferrite phase and the concentration of fracture sites in the austenite phase happened in the VD samples. As a result, ductility or elongation performance was better in this direction; 3): More grain boundary hardening can be expected in the HD samples which played a significant role in preventing the deformation of the austenite phase. As a result, more fracture area was found in the ferrite phase in the HD sample, as shown in Fig. 10(d). Therefore, the UTS was higher in this direction.

However, no apparent anisotropy of Rp0.2 (YS) was found in this material. The nitrogen work hardening effect gives a rational explanation for this in the early deformation stage. As observed and analyzed above, the Widmanstätten austenite predominated the austenite phase and took the leading role during deformation. Therefore, the nitrogen content in WA in different positions was measured, as shown in Fig. 13. In the last layer, the average content of nitrogen in WA is close to that in the wire $(0.22 \mathrm{wt}$. \%). The same average content $(0.57 \mathrm{wt} . \%)$ was found in the wall-body and the root region; however, higher errors existed in the root-region. According to [49], for high nitrogen stainless steels (N\%>0.4 wt.\%), solid solute nitrogen in austenite grains would cause the dislocations arraying and forming the planer morphology in $\{111\}$ planes which provided the strengthening effect with no loss of ductility. In this study, a large number of dislocation planes was found in the VD sample pointed by white arrows in Fig. 14(a). The diffraction pattern in the red dot was shown in Fig. 14(c), and the viewing direction is $\left[\begin{array}{l}0 \\ 11\end{array}\right]$. The highest reflection intensity was located in $\{111\}$ planes and followed by $\{200\}$. The results corresponded precisely with the austenite peaks in the XRD results; as a result, planer dislocations were confirmed in the nitrogen contained austenite phase. For the ferrite phase, with a BCC lattice structure, the strengthening effect was mainly caused by the dislocation tangling, as can be seen in Fig. 14(c) by the light green arrows in the HD sample, 
and also found little in the Fig. 14(a). The diffraction pattern in the blue dot was shown in Fig.

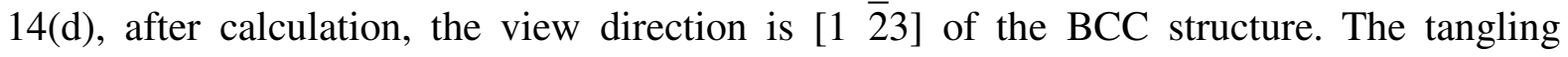
dislocation strengthening mechanism was verified for the ferrite phase. Usually, the austenite phase has higher ductility but lower strength than the ferrite phase. However, in this case, the strength of the austenite phase in the VD samples was intensified by the nitrogen work hardening effect with the form of planer dislocations. As a result, the difference of YS in these two directions were eliminated in the very early deformation period.

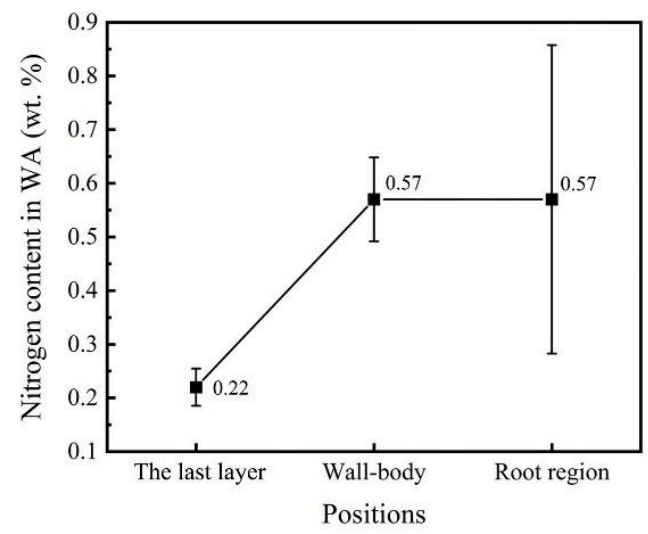

Fig. 13 Nitrogen content in the Widmanstätten austenite (WA) in different positions (three EDS spots were detected in each position, and the mean values and error bars were calculated by using the AVERAGE and STDEV functions in EXCEL, separately.) 

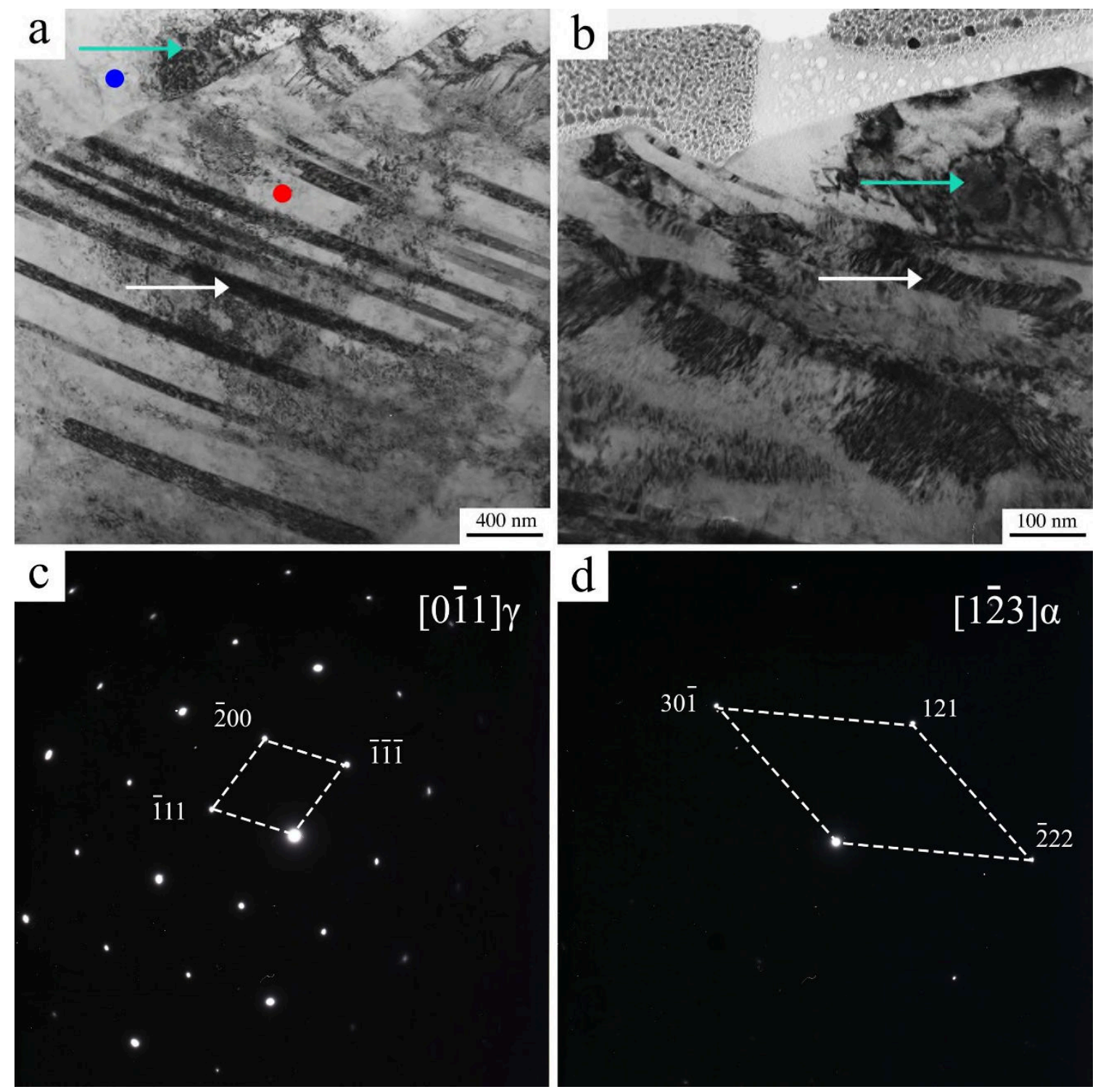

Fig.14 TEM image taken from the fracture area of the (a) VD and (b) HD sample, the diffraction patterns in (c) and (d) were taken from the red and blue dot in (a), separately.

\section{Conclusion}

The microstructure and mechanical properties of the high-alloyed SDSS (ER2594) processed by TOPTIG-WAAM were investigated. With the analysis of microstructure, crystal characterizations and the mechanical performances, the following are specific conclusions drawn from the results of this research:

- TOPTIG-WAAM method was successfully used to process SDSS structure, and a relatively high austenite content $(98.45 \mathrm{wt} . \%)$ was found in the wall-body with little ferrite content (1.55 wt.\%) based on the XRD analysis.

- The massive growing of austenite phase in the wall-body region was mainly caused by the continuous propagation of intergranular secondary austenite which resulted in the coarsening of primary austenite. Meanwhile, a certain amount of intragranular secondary austenite was revealed gathering in the positions $(0-493.8 \mu \mathrm{m})$ near to the 
layer band. Both the growing of intergranular secondary austenite and the precipitation of intragranular secondary austenite were closely related to the precipitation of chromium nitrides. Chromium nitrides acted as pioneers for the former and played a role as nuclei for the latter.

- Deleterious intermetallic phase, such as $\lambda$ and $\sigma$, was found not a significant problem for the fracture of the as-deposited material, however, precipitation of $\mathrm{CrN}$ and existence "inclusions" ( $\mathrm{Cr} 2 \mathrm{~N}$ and impurities) took the part responsible for the uneven distribution of elongation in the HD samples and the low impact toughness in the head and the root regions, separately.

- Excellent mean tensile properties were obtained as $\mathrm{R}_{\mathrm{p} 0.2}(530 \mathrm{MPa})$, ultimate strength (852MPa) and elongation (35\%), and minor uneven distribution of tensile properties were presented in the same direction (VD or HD) in the wall-body. The range of impact toughness was addressed between $104.21-122.24 \mathrm{~J} / \mathrm{cm}^{2}$. The main difference was brought out by the nonuniform balance of austenite and ferrite phase in the last layer (51.78/48.22) and root region (84.77/15.23), according to the XRD results.

- Nitrogen was found to be a promising element in diminishing the anisotropy of YS due to the nitrogen work hardening effect. However, nitrogen revealed no visible impact on UTS and elongation as the interruption of strong directional growth of ferrite columnar in VD. In this study, the HD samples got higher UTSs along with lower elongations when compared with the VD samples.

\section{Acknowledgments}

The authors wish to acknowledge the financial support from Nanjing University of Science and Technology Scholarship (No. AE91309), National Nature Science Foundation of China (No:51505226) and the technician members of the Welding Engineering and Laser Processing Centre, Cranfield University. The authors would like to thank Dr. Xianwei Liu for the assistance during the SEM, EBSD and TEM analysis. Besides, many thanks to Dr. Anatolii Babutskyi from Hertfordshire University for the assistance with the impact tests.

Conflicts of Interest: The authors declare no conflict of interest.

\section{References}

[1] J.C. Lippold, D.J. Kotecki, Welding Metallurgy and Weldability of Stainless Steel, John Wiley \& Sons, USA, 2014.

[2] S.W. Williams, F. Martina, A.C. Addison, J.L. Ding, G. Pardal, P. Colegrove, Wire + Arc Additive Manufacturing, Materials Science and Technology 32 (2016) 641-647.

[3] W.E. Frazier, Metal Additive Manufacturing: A Review, Journal of Materials Engineering and Performance 23 (2014) 1917-1928.

[4] D.G. Ahn, Direct metal additive manufacturing processes and their sustainable applications for green technology: A review, International Journal of Precision Engineering and Manufacturing-Green Technology 3 (2016) 381-395. 
[5] S. Kou, Welding Metallugry, John Wiley \& Sons, USA, 2003.

[6] K.F. Ayarkwa, S.W. Williams, J.L. Ding, Assessing the effect of TIG alternating current time cycle on aluminium wire + arc additive manufacture, Additive Manufacturing 18 (2017) 186-193.

[7] Y. Ma, D. Cuiuri, N. Hoye, H.J. Li, Z.X. Pan, The effect of location on the microstructure and mechanical properties of titanium aluminides produced by additive layer manufacturing using in-situ alloying and gas tungsten arc welding, Materials Science and Engineering: A 631 (2015) 230-240.

[8] Z.W. Qi, B.Q. Cong, B.J. Qi, H.Y. Sun, G. Zhao, J.L. Ding, Microstructure and mechanical properties of double-wire + arc additively manufactured $\mathrm{Al}-\mathrm{Cu}-\mathrm{Mg}$ alloys, Journal of Materials Processing Technology 255 (2018) 347-353.

[9] D. Clark, M.R. Bache, M.T. Whittaker, Shaped metal deposition of a nickel alloy for aero engine applications, Journal of Materials Processing Technology 203 (2008) 439-448.

[10] K. Davidson, S. Singamneni, Selective Laser Melting of Duplex Stainless Steel Powders: An Investigation, Materials and Manufacturing Processes 31 (2015) 1543-1555.

[11] K. Saeidi, L. Kevetkova, F. Lofaj, Z. Shen, Novel ferritic stainless steel formed by laser melting from duplex stainless steel powder with advanced mechanical properties and high ductility, Materials Science and Engineering: A 665 (2016) 59-65.

[12] F. Hengsbach, P. Koppa, K. Duschik, M.J. Holzweissig, M. Burns, J. Nellesen, W.Tillmann, T. Tröster, K.P. Hoyer, M. Schaper, Duplex stainless steel fabricated by selective laser melting - Microstructural and mechanical properties, Materials \& Design 133 (2017) 136-142.

[13] G. Posch, K. Chladil, H. Chladil, Material properties of CMT-metal additive manufactured duplex stainless steel blade-like geometries, Welding in the World 61 (2017) 873-882.

[14] S. Pantelakis, Magnus Eriksson, Malin Lervåg, Camilla Sørensen, Andreas Robertstad, Bård M. Brønstad, Bård Nyhus, Ragnhild Aune, Xiaobo Ren, Odd M. Akselsen, S. Koubias, Additive manufacture of superduplex stainless steel using WAAM, MATEC Web of Conferences 188 (2018).

[15] Y.Z. Yang, Z.Y. Wang, H. Tan, J.F. Hong, Y.M. Jiang, L.Z. Jiang, J. Li, Effect of a brief post-weld heat treatment on the microstructure evolution and pitting corrosion of laser beam welded UNS S31803 duplex stainless steel, Corrosion Science 65 (2012) 472-480.

[16] H.B. Geng, J.L. Li, J.T. Xiong, X. Lin, F.S. Zhang, Optimization of wire feed for GTAW based additive manufacturing, Journal of Materials Processing Technology 243 (2017) 40-47. 
[17] T. Opderbecke, S. Guiheux, TOPTIG: robotic TIG welding with integrated wire feeder, Welding International 23 (2009) 523-529.

[18] C.S. Wu, Welding Thermal Processes and Weld Pool Behaviour, CRC Press, 2011.

[19] Z.Q. Zhang, H.Y. Jing, L.Y. Xu, Y.D. Han, L. Zhao, Investigation on microstructure evolution and properties of duplex stainless steel joint multi-pass welded by using different methods, Materials \& Design 109 (2016) 670-685.

[20] S. Ganguly X.F. Xu, J.L. Ding, S. Guo, S.W. Williams, F. Martina, Microstructural evolution and mechanical properties of maraging steel produced by wire + arc additive manufacture process, Materials Characterization (2017).

[21] X.Y. Zhang, Q. Zhou, K.H. Wang, Y. Peng, J.L. Ding, J. Kong, S. Williams, Study on microstructure and tensile properties of high nitrogen $\mathrm{Cr}-\mathrm{Mn}$ steel processed by CMT wire and arc additive manufacturing, Materials \& Design 166 (2019).

[22] X. Xu, S. Wessman, J. Odqvist, S. M. King, P. Hedström, Nanostructure, microstructure and mechanical properties of duplex stainless steels $25 \mathrm{Cr}-7 \mathrm{Ni}$ and $22 \mathrm{Cr}-5 \mathrm{Ni}$ (wt.\%) aged at $325^{\circ} \mathrm{C}$, Materials Science and Engineering: A 754 (2019) 512-520.

[23] N. Pettersson, R. F. A. Pettersson, S. Wessman, Precipitation of Chromium Nitrides in the Super Duplex Stainless Steel 2507, Metallurgical and Materials Transactions A 46 (2015) 1062-1072.

[24] Z.Q. Zhang, H.Y. Jing, L.Y. Xu, Y.D. Han, G.L. Li, L. Zhao, Investigation on Microstructure and Impact Toughness of Different Zones in Duplex Stainless Steel Welding Joint, Journal of Materials Engineering and Performance 26 (2016) 134-150.

[25] B. Varbai, F. Tolnai, K. Majlinger, Effects of TIG Reheating on Duplex Stainless Steel Weld Microstructure, International Journal of Engineering and Management Sciences 4 (2019) 295-302.

[26] C. Garzon, A. Ramirez, Growth kinetics of secondary austenite in the welding microstructure of a UNS S32304 duplex stainless steel, Acta Materialia 54 (2006) 3321-3331. [27] H.P. Liu, X.J. Jin, Secondary Austenite Morphologies in Fusion Zone of Welded Joint after Postweld Heat Treatment with a Continuous Wave Laser, Journal of Materials Science \& Technology 28 (2012) 249-254.

[28] S. Atamert, Super duplex stainless steels Part 1 Heat affected zone microstructures, Materials Science and Technology 8 (1992) 896-911.

[29] A.J. Ramirez, S.D. Brandi, J.C. Lippold, Secondary austenite and chromium nitride precipitation in simulated heat affected zones of duplex stainless steels, Science and 
Technology of Welding and Joining 9 (2004) 301-313.

[30] C. H. X. M. Magalhães, G. L. Faria, L. E. Lagoeiro, J. D. Silva, Characterization of the Austenite Reformation Mechanisms as a Function of the Initial Ferritic State in a UNS S32304 Duplex Stainless Steel, Materials Research 20 (2017) 1470-1479.

[31] A.J. Ramirez, J.C. Lippold, S.D. Brandi, The Relationship between Chromium Nitride and Secondary Austenite Precipitation in Duplex Stainless Steels, Metallurgical Transactions A 34A (2003) 1575-1597.

[32] Z.Q. Zhang, H.Y. Jing, L.Y. Xu, Y.D.Han, L. Zhao, J.L. Zhang, Influence of microstructure and elemental partitioning on pitting corrosion resistance of duplex stainless steel welding joints, Applied Surface Science 394 (2017) 297-314.

[33] J.C. Lippold, A.M. Al-Rumaih, Duplex Stainless Steels '97, Proc. Conf., The Netherlands, 1005-1010.

[34] S.D. Brandi, J.C. Lippold, W. Lin, Duplex Stainless Steels '97, Proc. Conf., The Netherlands, 411-418.

[35] Zhiqiang Zhang, Hongyang Jing, Lianyong Xu, Yongdian Han, Lei Zhao, Xiaoqing Lv, Jianyang Zhang, Influence of heat input in electron beam process on microstructure and properties of duplex stainless steel welded interface, Applied Surface Science 435 (2018) 352366.

[36] Z.Q. Zhang, H.Y. Jing, L.Y. Xu, Y.D. Han, L. Zhao, The influence of microstructural evolution on selective corrosion in duplex stainless steel flux-cored arc welded joints, Corrosion Science 120 (2017) 194-210.

[37] A. Pramanik, G. Littlefair, A. K. Basak, Weldability of Duplex Stainless Steel, Materials and Manufacturing Processes 30 (2015) 1053-1068.

[38] K. Migiakis, N. Daniolos, G. D. Papadimitriou, Plasma Keyhole Welding of UNS S32760 Super Duplex Stainless Steel: Microstructure and Mechanical Properties, Materials and Manufacturing Processes 25 (2010) 598-605.

[39] S. Hertzman, J. Charles, On the effect of nitrogen on duplex stainless steels, Revue de Métallurgie 108 (2012) 413-425.

[40] A. Eghlimi, M. Shamanian, M. Eskandarian, A. Zabolian, J.A. Szpunar, Characterization of microstructure and texture across dissimilar super duplex/austenitic stainless steel weldment joint by austenitic filler metal, Materials Characterization 106 (2015) 208-217.

[41] S.Q. Wen, Metallurgical Evaluation of Cast Duplex Stainless Steels and Their Weldments, University of Tennessee 2001. 
[42] Y. Song, N.A. Mcpherson, T. N. Baker, The Effect of Welding Process on the Chi Phase Precipitation in As-welded 317L Weld Metals, ISIJ International 36 (1996).

[43] A. F. Padilha, P. R. Rios, Decomposition of Austenite in Austenitic Stainless Steels, ISIJ International 42 (2002) 325-337.

[44] V. A Hosseini, L. Karlsson, D. Engelberg, S. Wessman, Time-temperature-precipitation and property diagrams for super duplex stainless steel weld metals, Welding in the World 62 (2018) 517-533.

[45] M. Schwind, J. Kallqvist, J.-O. Nilsson, J. Agren, H.-O. Andren, S-Phase Precipitation in Stabilized Austenitic Stainless Steels, Acta Materialia 48 (2000) 2473-2481.

[46] S. Atamert, J.E. King, Sigma-phase formation and its prevention in duplex stainless steels, Journal of Materials Science Letters 12 (1993) 1144-1147.

[47] I.F. Machado, P.A. Carvalho, A.F. Padilha, Austenite Instability and Precipitation Behavior of High Nitrogen Stainless Steels. In Stainless Steels: Microstructure, Mechanical Properties and Methods of Applications; Animesh Kumar Basak Publishing, New York, 2016.

[48] J.W. Simmons, Overview: high-nitrogen alloying of stainless steels, Materials Science and Engineering: A A207 (1996) 159-169.

[49] S. Kubota, Y. Xia, Y. Tomota, Work-hardening Behavior and Evolution of Dislocationmicro-structures in High-nitrogen Bearing Austenitic Steels, ISIJ International 38 (1998) 474481. 
2019-07-02

\section{Microstructure and mechanical}

properties of TOP-TIG-wire and arc

additive manufactured super duplex

stainless steel (ER2594)

\section{Zhang, Xiaoyong}

Elsevier

Zhang X, Wang K, Zhou Q, et al., (2019) Microstructure and mechanical properties of TOP-TIG-wire and arc additive manufactured super duplex stainless steel (ER2594), Materials Science and Engineering A: Structural Materials: Properties, Microstructures and Processing, Volume 762, August 2019, Article number 138097

https://doi.org/10.1016/j.msea.2019.138097

Downloaded from Cranfield Library Services E-Repository 